\title{
REUNIÓ TÈCNICA PER LA NORMALITZACIÓ DE NOMS I TEXTES D'ORIGEN ÀRAB
}

Por

LLÚCIA MARTIN I PASCUAL

Les influències lingüistiques i culturals de l'àrab en la llengua i cultura catalanes són molt nombroses, sobretot al sud del Principat, les llles i tot el País Valencià el legat és major. És en aquests indrets on podem trobar la marca del moresc en la llengua, les tradicions, la cultura popular; car, no debades, convisqueren sarrains i repobladors des del segle XII fins el XVII.

Actualment hi ha un corrent moròfil que es transllueix no sols en la literatura de creació, sinó en les noves orientacions d'investigació erudites, que intenten desxifrar les influències àrabs en la literatura i pensament catalanes des de l'Edat Mitjana; un tema que anirà completant el panorama general de les nostres lletres.

Però l'auge de les publicacions en català sobre temes àrabs va plantejar una sèrie de problemes en la transcripció al català de nom i textes d'origen àrab. Aquests problemes es feien palesos a Sharq Al-Andalus, única revista d'arabisme que publica regularment articles en català, i en altres llibres d'història àrab que estan publicant-se actualment, escrits en català.

A finals d'octubre de 1986 va tindre lloc a la Universitat d'Alacant una reunió tècnica per tal d'elaborar unes propostes de transcripció de nom d'origen àrab al català. Hi participaren dotze experts: els Drs. Joan Solà, Antoni Ferrando i Joan Miralles, catedràtics de Filologia Catalana per les Universitats de Barcelona-Central, València i Balears; els Drs. Federico Corriente i Maria Jesús Rubiera, catedràtics d'Estudis Arabs i Islàmics de les Universitats de Madrid-Complutense i Alacant; els Drs. Leonor Martínez, Dolors Bramon i Mikel d'Epalza, professors titulars d'àrab i estudis islàmics de les Universitats de Barcelona-Central, Saragossa i Alacant; el Prof. Lluís Polanco, de la Universitat de València; el Dr. Enric Llobregat, secretari del Consell de Cultura de la Generalitat Valenciana; Alberto Gómez Font, corrector de I'agència EFE i Joseba Intxausti, de l'UZEl, per la normalització de l'euskera. 
Els professors participants treballaven sobre una documentació aportada previament pel Dr. Mikel d'Epalza on es detallaven els punts que calia discutir i normalitzar. Alberto Gómez Font va cedir un annexe sobre els intents de normalització que s'havien fet en castellà i podien resultar orientadors per al català.

Els temes tractats es poden classificar en els següents capítols:

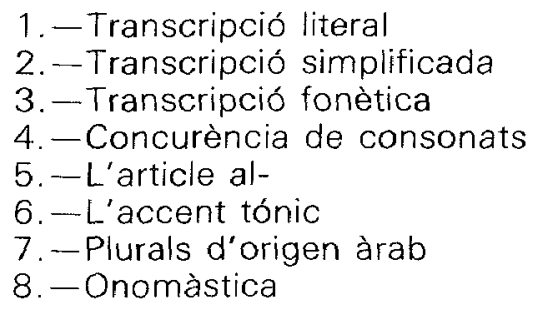

Respecte els tres sistemes de transcripció, hem de dir que, en principi, n'hi havien proposats només dos: un que en realitat seria "transliteració", amb la finalitat de reproduir els grafemes àrabs en grafemes catalans, sense allunarse dels sistemes establerts per altres liengües romàniques. Un segon sistema seria l'anomenat "de transcripció fonètica», la finalitat del qual és reproduir en el sistema grafemàtic català la fonètica àrab de la forma més aproximada possible i sense emprar signes diacrítics, que sí serien necessaris en el primer sistema descrit. Es tractaria, doncs, d'una transcripció simplificada.

Però, al llarg de la reunió, es va arribar a la conclusió que es podia proposar un tercer sistema, sense que tal idea arribés a desenvolupar-se totalment. Heus ací la proposta final:

- Un sistema de transcripció literal: correspon a la recomanació R-233 del ISO per la llengua catalana. Es el sistema emprat per la Gran Enciclopèdia Catalana amb lleugeres variants. Inclou signes diacrítics que permeten reconstruir el texte àrab original:

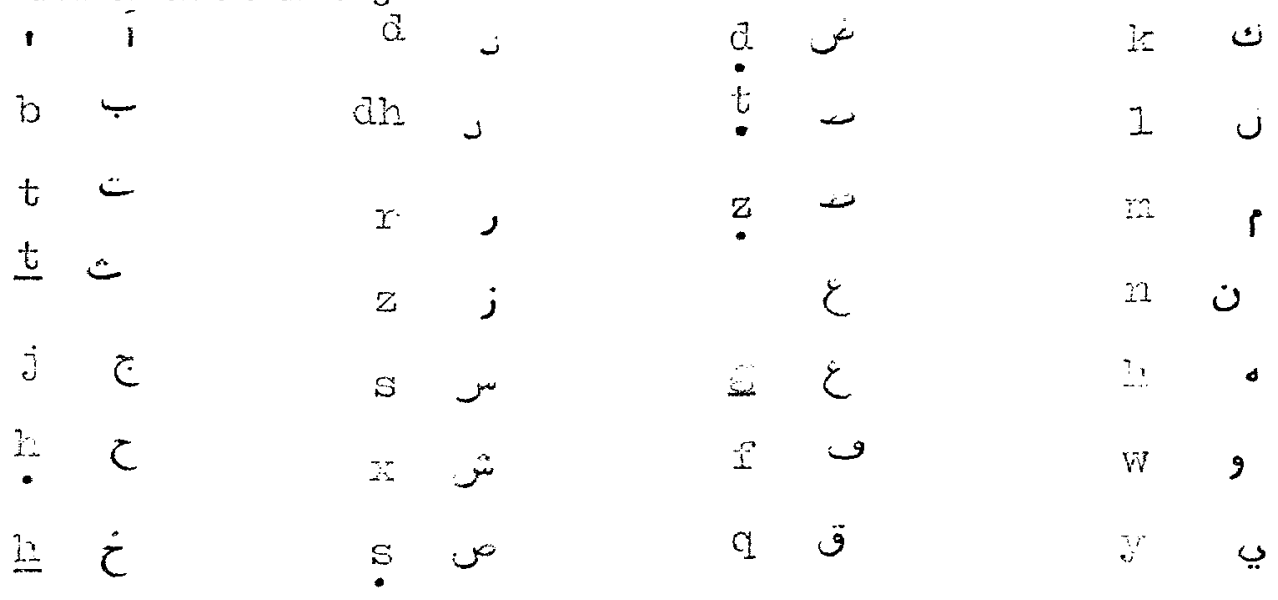


- Un sistema de transcripció simplificada, la finalitat del qual és reproduir els sons àrabs sense emprar signes gràfics que no es troben en català. Aquest sistema anirà adreçat a escrits més científics sense la necessitat de fer una transliteració que podria resular un tanto estranya per aquells que no estan familiaritzats en qüestions d'escriptura àrab:

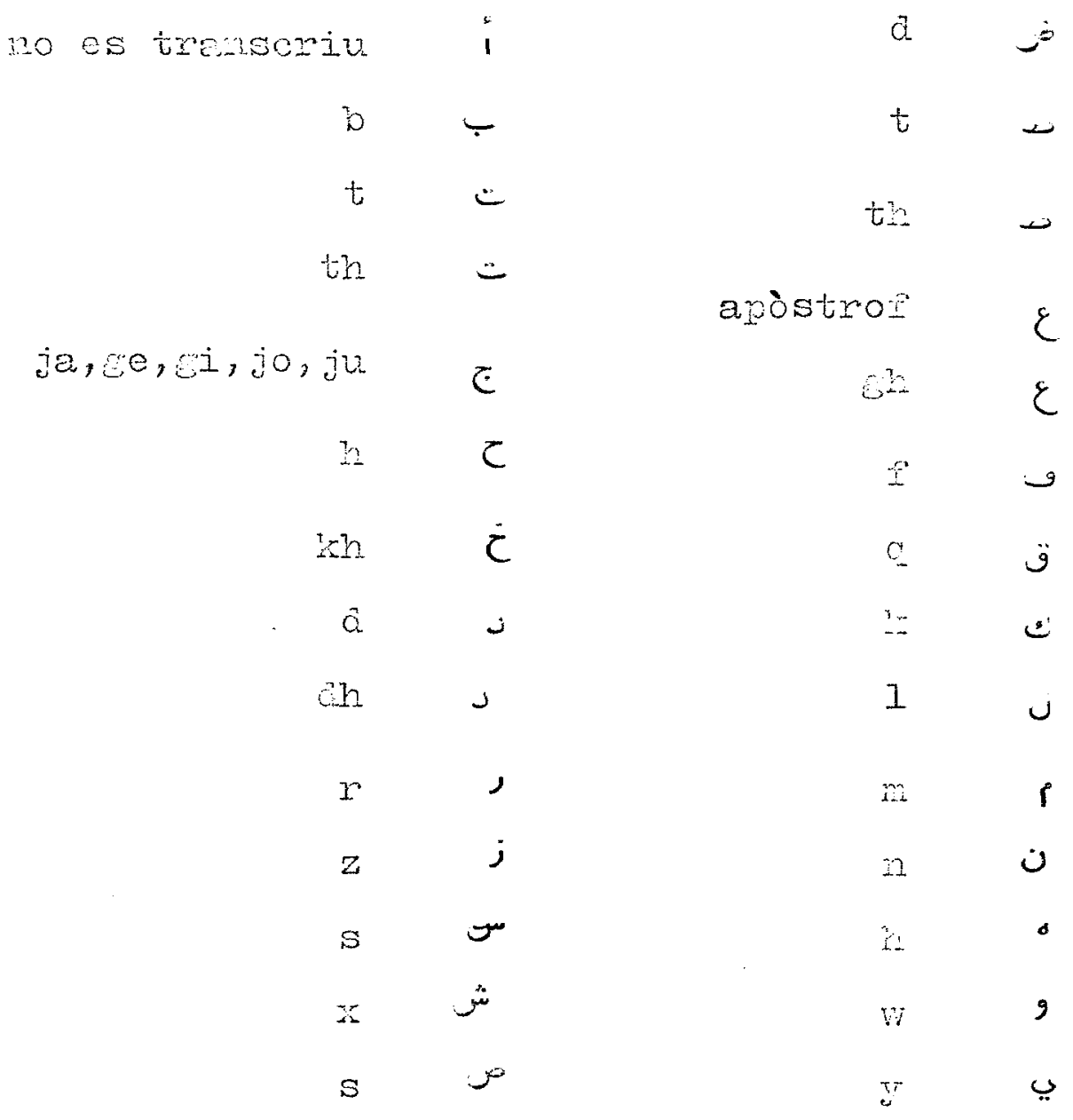


- Un tercer sistema, aquest sí, de transcripció fonètica adreçat als escriptors de divulgació i la premsa. Intentaria canalitzar la catalanització de préstecs àrabs. Aquesta proposta no va tenir èxit per creure que suposava una deformació de l'àrab originari i tampoc hi ha massa estudis sobre la matèria on recolzar-se. Aquest sistema va estar defensat pels professors Polanco, Gómez Font i Epalza. Al mateix temps, hi van presentar dues propostes de transcripció fonètica: una per part del Dr. Epalza i l'altra per Albeto Gómez Font, elaborada pensant en els mitjans de comunicació:

Pro oste de? Dr. Tnat.ra

$j a, g e, s i, j o, j u$

飞<smiles>[Mg][Mg][Mg]</smiles>

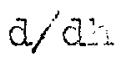

$r$

$z / S$ intervocèlice

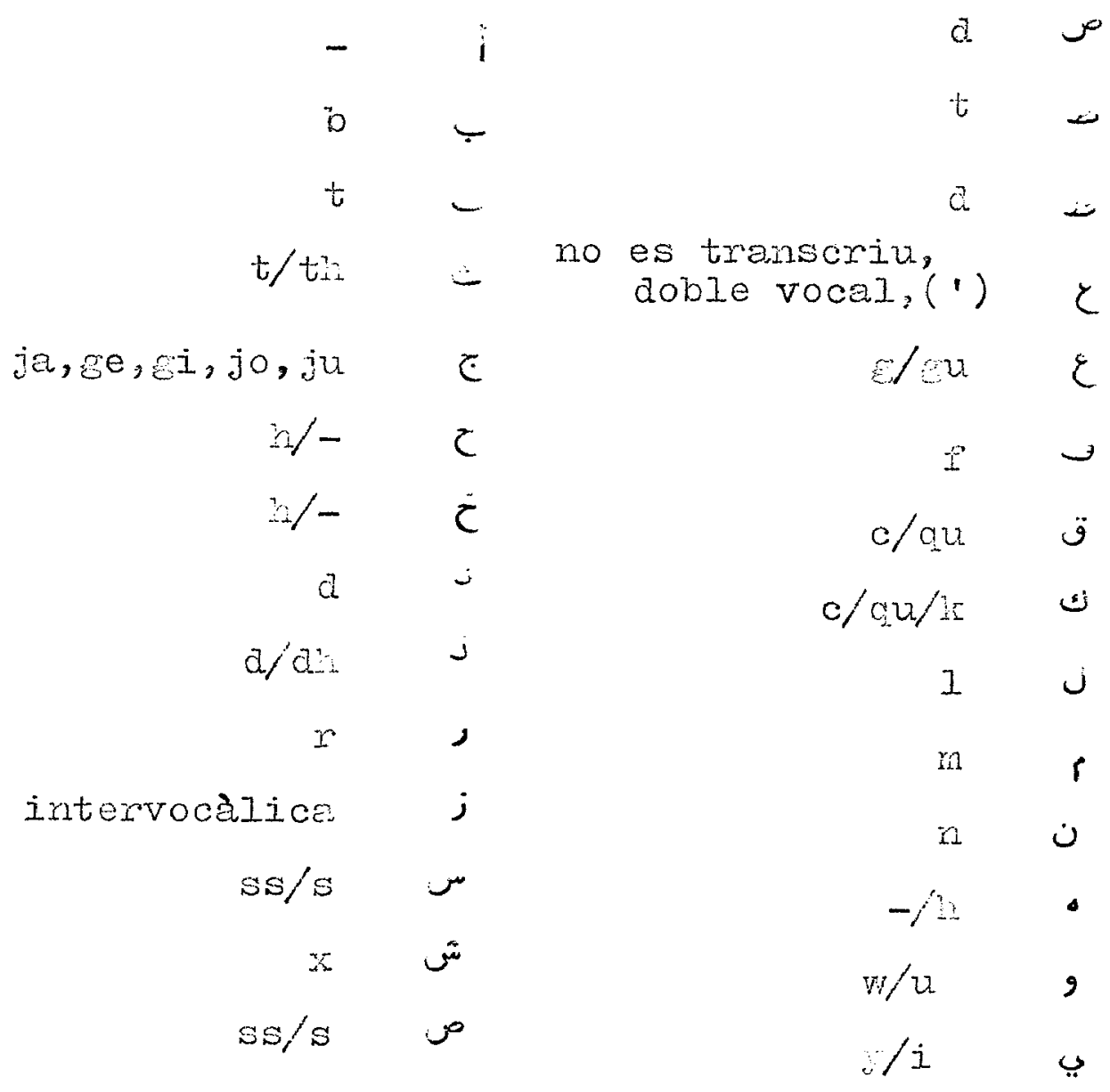

Pronosta de it herto fónar Font 


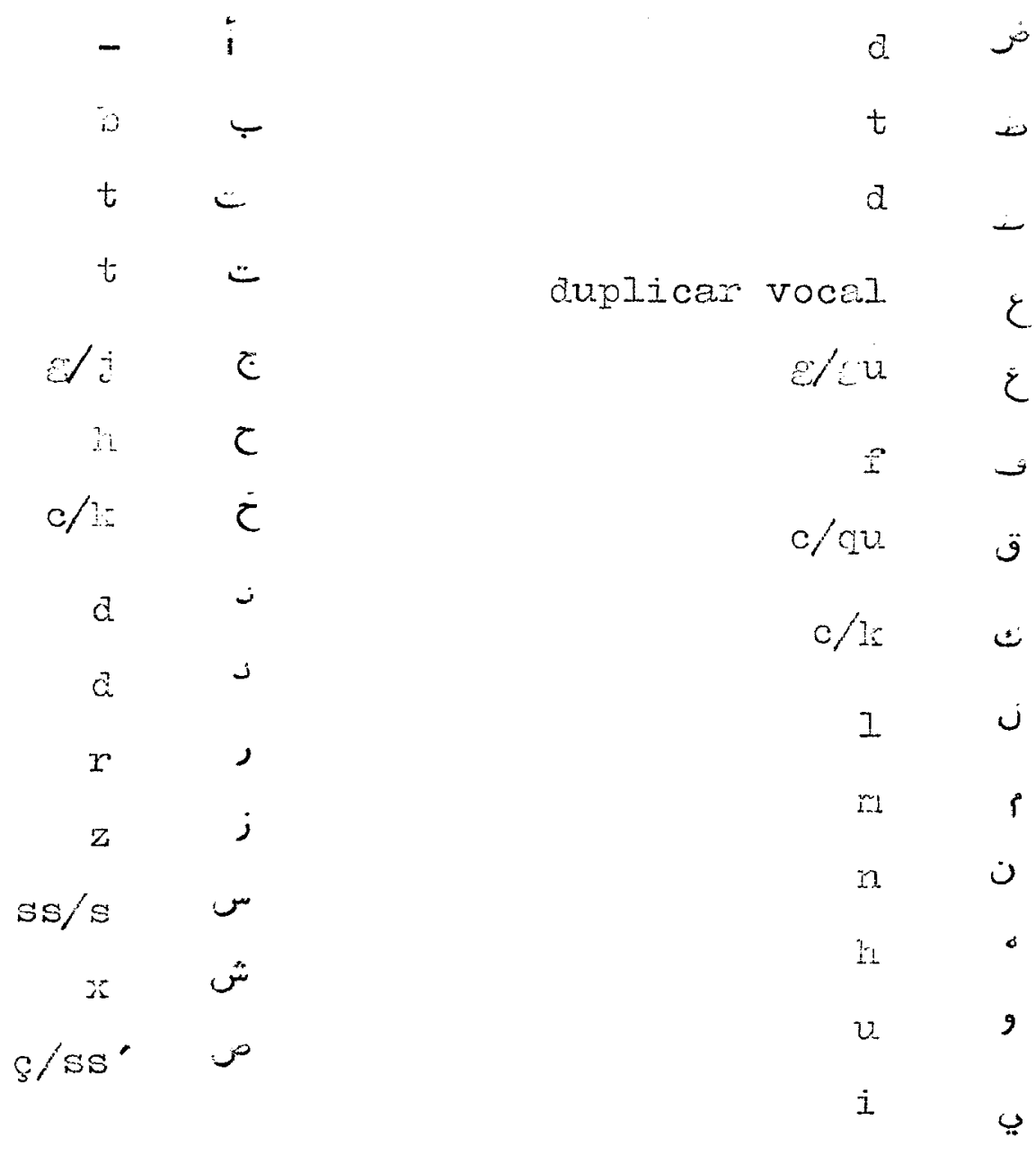

Respecte les altres qüestions que es tractaren, farem ací un resum.

La geminació o concurència de consonants. En àrab el taxdid. Plantejava el problema de la duplicació de consonants en català, si bé en molts parlars la geminació és un fet comú. En transcripció fonètica es rebutjarien totes aquelles geminades estranyes al català; però en transcripció simplificada o fonemàtica (el segon tipus proposat) es podien perdre els elements consonàntics significatius de l'àrab, per la qual cosa es proposà mantenir totes les confluències consonàntiques, tenint en compte que els dígrafs només dupliquen el primer element i la / duplica /.I 
L'article al-. Presenta una sèrie de problemes:

- Davant les lletres anomenades "solars" la / s'assimila a la següent, duplicant-la en la transcripció simplificada. En transcripció fonètica s'escriuria fent I'assimilació. En la transliteració en mantendria l.

- L'alif wasla de I'article, que no es pronuncia quan va darrere d'una paraula que acaba en vocal, desapareix.

- L'article va unit directamente a la paraula, sense guionet: per exemple, bab- albab; zuqaq- azzuqaq.

- En cas de duplicació de I, es posa I.I.

L'accent gràfic. L'àrab no té un sistema d'accentuació vocàlica, en canvi té un sistema quantitatiu, vocals llargues i breus. El català, com les altres llengües romàniques, representa l'accent, no la quantitat. En un sistema de transcripció proper al català s'ha de tenir en compte la situació de l'accent tònic per posar-hi l'ortogràfic. Proposem seguir les normes de l'accentuació àrab més generalitzades a la llengua culta internacional, tot i respectant la pronunciació deis noms dits tradicionalment en dialectal.

Les regles d'accentuació de l'àrab standar són:

- L'última sil.laba només porta accent tònic en alguns monosil.labs (generalment imperatius), en el morfema dual i en els adjectius acabats en -iyy, per tractar-se d'una sil. laba llarga.

- La penúltima sil. Jaba porta l'accent quan és llaga: és a dir, si la vocal porta consonant de prolongació o quan és una vocal breu entre dues consonants.

- En paraules de més de dos sil. labes que no tinguen les característiques anteriors, l'accent es remonta fins que troba una vocal llarga o bé el principi de la paraula. catalá:

Els plurals dels noms d'origen àrab. Fan els plurals segons les regles del

els acabats en -í fan el plural -ins

els acabats en -a fan el plural en -ans

Onomàstica. Decidiren mantenir els noms ja tradicionals com Almenara, Mahoma, etc. També, mantenir l'article en els noms propis. Els noms que comencen per Abd, Abu, Ibn i altres compostos, aniran units per un guionet de forma que es vegi que hi ha una relació entre els dos elemnts del nom y són inseparables. Hom proposà escriure'Is seguits, però hi havia el problema de fer paraules massa llargues. Alguns exemples: Saif-Addawla, Abu-Sufyan, 'Abdu-Rrahman. 
Quan a la toponímia es proposava aplicar la transcripció simplificada a menys que es tracti de noms ja tradicionals en català, que caldria respectar-los.

Totes aquestes recomanacions i propostes se portaren a diverses instàncies, especialmente a l'Institut d'Estudis Catalans, esperant I'aprovació definitiva, després de la qual es difondran a tots els mitjans de comunicació.

Encara hi ha problemes a resoldre com els que han quedat pendents en la transcripció, altres a nivell lèxic, onomàstica, literatura, etc. Aquesta reunió va suposar un primer pas en l'estudi i aproximació a tots aquests temes, $i$, de segur, tindrà continuïtat. 